\title{
Research on the Relationship among M\&A Behavior, Investment Efficiency and Firm Value-Empirical Evidence from A Shares of Listed Corporations
}

\author{
Xixi Feng \\ Department of Management, Jinan University, Guangzhou, China \\ Email: fengxixijj@126.com \\ Received 20 April 2016; accepted 2 May 2016; published 5 May 2016 \\ Copyright (C) 2016 by author and Scientific Research Publishing Inc. \\ This work is licensed under the Creative Commons Attribution International License (CC BY). \\ http://creativecommons.org/licenses/by/4.0/ \\ (c) (i)

\begin{abstract}
In this paper, we use the data of A shares of listed corporations from 2010 to 2014 to research the relationship among the efficiency of investment, acquisition behavior and corporation value. The results show that the enterprise acquisition behavior and enterprise value have no significant correlation. While the investment efficiency of enterprises will be affecting the relationship between the two, as the same words, the higher the efficiency of investment, the influence of mergers and acquisitions to increase the role of the enterprise value is more significant. According to the above conclusions, this paper puts forward related suggestions.
\end{abstract}

\section{Keywords}

Investment Efficiency, Acquisition Behavior, Corporation Value

\section{Introduction}

Mergers and Acquisitions (M\&A) can make it possible for enterprise to increase the company's capital quickly and expand the scale of the company. Whether horizontal or vertical mergers and acquisitions will optimize the allocation of resources, synergies or economies of scale will enhance the value of the enterprise. But not all mergers and acquisitions can make enterprises to enhance the value of the enterprise; there are many cases of failure in history. In addition, the investment efficiency also has a decisive influence on the enterprise value. If enterprises want to raise their fundamental value, it's necessary for them to try to improve the efficiency of investment. 
At present, many people at home and abroad have studied the subjects about efficiency of investment and mergers and acquisitions, whether the enterprise acquisition behavior can improve the enterprise value, and also many articles have been analyzed concretely. But the relationship among enterprise acquisition behavior, investment efficiency and firm value is not been researched universally.

Our sample consists of all relevant data of the acquisition behavior of the A-share listed companies years between 2010-2014. This paper investigates the relationship among enterprise acquisition behavior, investment efficiency and firm value. Specifically, it analyzes whether the enterprise acquisition behavior has a significant influence on corporation value and judges whether the investment efficiency can affect the relationship between acquisition behavior and corporation value. In this paper, through analyzing the relationship among enterprise acquisition behavior, investment efficiency and firm value empirically, we provide advice and direction for the investment behavior of enterprises and small and medium investors.

\section{Theoretical Analysis and Research Hypothesis}

Theoretical study on the mergers and acquisitions develop earlier in the western countries, since the sixties of the 19th century, many western scholars have begun to research on mergers and acquisitions. Langtieg, Magenhiem (1978) and Mueller (1988) classified M\&A companies by industry classification, in order to studied and compared in the industry, through a comparative analysis of the large-scale data, they came to the conclusion that in the long run, the performance of Listed Companies which have acquisition behavior has not been significantly improved, and even individual enterprises performance had a decreasing trend in the long-term [1]. Jarrel (1988), and Bradley (1989) take the different financial indicators analyzed the same samples, but found a completely different phenomenon. They found that mergers and acquisitions did not lead to the decreases of the long-term performance of enterprises [2]. Palepu, Healy and Rubaek (1992), selected companies which had the acquisition behavior between 1979-1984 in the United States, and for the top 50 enterprises, they studied the indicators of business performance and profitability, such as operating cash flow and return on assets. The conclusion is that the indicators of the companies which had the acquisition behavior are significantly higher than other companies [3].

The development of China's securities market is rapidly. Therefore it contributed to China's academic research on the behaviors of mergers and acquisitions are more and more detailed. Xin Dan Li (1999) studied more than one hundred mergers and acquisitions enterprises and carry out a conclusion that M\&A activity can improve the companies' performance significantly on that year, but the affection to the long-term performance is not obvious [4]. Genfu Feng (2001) found that the affection of listing Corporation acquisition behavior on performance. As a whole, there is a trend from ascending to descending [5].

Mingshe Xu (2005) chose the sample of enterprises which merger and acquisition in the special field, and he researched the investment efficiency of these companies [6]. Yang Yunjie (2007), Lu Fucai (2009) studied the financing behavior of enterprises is how to influence the efficiency of investment, and the relationship between financing and investment activities of enterprises are studied and analyzed [7] [8].

According to the above conclusions, we can be found the relationship between acquisition behavior and companies' value is uncertain, and the relationship between efficiency of investment and acquisition behavior is certain, so that we get the following assumptions:

H1: No correlation between value and enterprise' acquisition behavior;

$\mathrm{H} 2$ : The higher the efficiency of investment, the influence of acquisition behavior on increase the enterprise' value is more significant.

\section{Research Design}

\subsection{Sample and Data}

This paper selected all A-share listed companies in Shanghai and Shenzhen stock markets data between 20112014 as the study sample and the original data were screening as follows: 1) selects the non ST companies; 2) excluding financial and insurance companies. These companies are different from the companies in other industries, this model does not apply to this kind of industry; 3) eliminate individual missing data of the company, and ultimately determine 38485 valid observations as example. The relevant data is from the database. Excel and Stata are used to deal with the data. 


\subsection{Variables}

1) Explained variables: this paper selects as a measure of the value of the enterprise. This paper selected Tobin $\mathrm{Q}$ of listing Corporation from CSMAR database as the measure of enterprise value directly. The definition of Q in this paper is the ratio of market value to the net value of assets minus net intangible assets and goodwill; when the denominator is not published, equal to zero or less than zero, $Q$ will be represented as null value.

2) Explanatory variables: a): This variable is set as a dummy variable B. If the Target Corp had acquisition behavior a year ago, the value of this variable is 1 , otherwise is 0 . b) Investment efficiency: This paper used ROE to measure the efficiency of investment. The definition of ROE is the ratio of net profit to the average interests of the shareholders. Shareholders' equity is equal to the average equity balance at the end of the period.

3) Control variables: a) Annual stock turnover ratio: The definition of annual turnover ratio is the total number of stock trading divided by the total number of shares in issue within a year. The frequency of stock trading can indicate investors' favor to the companies in stock market. If transactions are frequent, then the number of company's stock trading is commonly big, if not, then the company's stock trading relatively cold and cheerless, and bigger the monthly frequency of transactions means investors are more optimistic about the stock, and the demand is greater. This indicates the value of the company higher. b) The size of the company: The size of the company means the natural logarithm of the total assets of the company. The larger the size of the company, the more adequate resources it will have, the higher share of possession of the market. The company also can obtain more investment interests. So investors are more willing to invest large companies. c) Leverage ratio: This ratio refers to ratio that the company's long-term debt to total assets. The amount of debt can reflect the enterprise value and some relevant information. When the value of the enterprise is undervalued, the old shareholders tend to use debt to raise funds because of fear of the benefits go to new shareholders. So when the enterprise has a certain liability, it will be seen as a positive information. d) Total asset growth rate: Total assets of this period value-total assets of this period of initial value)/(total assets during the period of initial); when the denominator is not published, equal to zero or less than zero, the rate will be represented as null value. e) Operating receipt growth rate: (operating income of the single quarter of this year-operating income of the single quarter amount of last year)/(operating income of a single quarter amount of last year); when the denominator is not published, equal to zero or less than zero, the rate will be represented as null value; this variable is a single quarter chain index.

\subsection{Model Construction}

In order to study the relationship among enterprise acquisition behavior, investment efficiency and firm value, this paper designs the following model:

$$
\begin{gathered}
Q=\alpha_{0}+\alpha_{1} B+\alpha_{2} \text { Control }+\mu \\
Q=\beta_{0}+\beta_{1} B+\beta_{2} I V+\beta_{3} B \times I V+\beta_{4} \text { Control }+\varepsilon
\end{gathered}
$$

The model (1) is to verify the H1, model (2) verify the H2. In these models Q denotes enterprise value; B represents the merger and acquisition behavior of dummy variables; IV represents the investment efficiency and Control represents control variables, including annual turnover rate (TR), leverage ratio (LEV), total asset growth rate (TAT) and Operating receipt growth rate (RBR); $\mu$ and $\varepsilon$ represent random disturbance term.

If $\alpha_{1}$ is not significant at the $1 \%$ level of significance, then it indicates that the behavior of acquisition has no significant effect on the value of the enterprise. Otherwise the opposite. If $\beta_{1}$ is significant at the level of $1 \%$, and combined with the previous hypothesis, then we can get the conclusion that higher the efficiency of investment, the influence acquisition behavior to increase the value of the company is more significant, so that $\mathrm{H} 2$ is also right. If it is not significant, it shows that the investment efficiency will not affect the relationship between acquisition behavior and enterprise value.

\section{Empirical Analysis}

\subsection{Descriptive Statistics}

Descriptive statistics of the variables in this paper are shown in Table 1 . Table 1 shows that the maximum value of Tobin Q is 9.8398, the minimum value is 0.2306 , and the standard deviation is 1.8195 , which shows that the 
Table 1. Descriptive statistics of variables.

\begin{tabular}{cccccc}
\hline Variable & Sample size & Mean & Max & Min & Standard deviation \\
\hline Q & 38485 & 2.2091 & 9.8398 & 0.2306 & 1.8195 \\
IV & 38485 & 0.0700 & 0.3373 & -0.4720 & 0.1023 \\
LEV & 38485 & 0.4340 & 0.8884 & 0.0454 & 0.2125 \\
TR & 38485 & 539.2497 & 1919.988 & 65.5665 & 368.9055 \\
TAT & 38485 & 0.0968 & 1.1359 & -0.2219 & 0.1975 \\
RBR & 38485 & 0.2534 & 10.3252 & -0.9080 & 1.2757 \\
\hline
\end{tabular}

enterprise value of the sample has a big difference. The maximum investment efficiency is 0.3373 , the minimum value is -0.4720 , which shows that the investment efficiency of some enterprises is 0 , but the standard deviation is 0.1023 , which shows that the investment efficiency of these enterprises in the sample is not so much different.

\subsection{Correlation Analysis}

Table 2 reflects the correlation coefficients among the variables in the two models. It can be seen from the second column that the explanatory variables B, B*IV, IV are significantly positively correlated with the explanatory variables $\mathrm{Q}$ at the $1 \%$ level, which is consistent with the $\mathrm{H} 1$ above. And the correlation coefficient between Q and B*IV is greater than the correlation coefficient between Q and IV, to a certain extent that it is consistent with the $\mathrm{H} 2$ above. In general, the control variables passed the significant test, which shows that they were significantly correlated with the explanatory variables. In these two models, the control variables can be controlled to make the conclusion more credible. However, the correlation among the independent variables in the two models is too high, and the risk of multiple linear regression model is need to be tested in the regression model.

\subsection{Regression Analysis}

\subsubsection{The Regression Analysis of Acquisition Behavior and Enterprise Value}

Table 3 shows the linear relationship between B and firm value Q. Adj. $R^{2}$ is 0.3287 , F value at 0.01 level and the equation is significant. What's more, the model fits well. Control industry and the return of the year show that there is no correlation between acquisition behavior and enterprise value. No matter whether the enterprise has the acquisition behavior, or the acquisition behavior is successful, the value of the enterprise will not be affected by any of them.

4.3.2. The Regression Analysis of Investment Efficiency, Acquisition Behavior and Enterprise Value Table 4 reflects the multiple linear relationship of investment efficiency (IV), acquisition behavior (B) and enterprise value (Q). Adj. $R^{2}$ is $0.3397, \mathrm{~F}$ value at 0.01 level and the equation is significant. What's more, the model fits well. Control for Industry and year after regression show that multiply the estimated coefficient of B*IV at the $1 \%$ level is significantly positive, indicating that the higher the efficiency of investment, the acquisition behavior to increase the enterprise value is more significant.

\section{Conclusions}

\subsection{The Results of the Study}

The results show that there is no correlation between the success of acquisition behavior and enterprise value. And investment efficiency will affect the relationship between the two, that is, the higher the efficiency of investment, the more significant the acquisition behavior to increase the value of the enterprise. The above research results indicate that enterprises with higher investment efficiency tend to be more likely after a thoughtful, detailed planning to make the M\&A decision, rather than a simply decision by the leader.

\subsection{Suggestions}

Based on the results of this study, this paper puts forward the following suggestions: 1) The enterprise is not 
Table 2. Correlation coefficient of each variable in the model.

\begin{tabular}{|c|c|c|c|c|c|c|c|}
\hline & Q & IV & B & LEV & TR & TAT & RBR \\
\hline $\mathrm{Q}$ & 1 & & & & & & \\
\hline IV & $0.1430^{* * *}$ & 1 & & & & & \\
\hline B & $0.0356^{* * *}$ & $0.0343^{* * * *}$ & 1 & & & & \\
\hline LEV & $-0.4582^{* * *}$ & $-0.0864^{* * *}$ & $-0.0410^{* * *}$ & 1 & & & \\
\hline $\mathrm{TR}$ & $0.1943^{* * *}$ & $-0.0993^{* * *}$ & $0.0234^{* * *}$ & $-0.2309^{* * *}$ & 1 & & \\
\hline TAT & $0.0187^{* * *}$ & $0.1508^{* * *}$ & $0.0279^{* * *}$ & $0.0598^{* * *}$ & $0.0128^{* *}$ & 1 & \\
\hline RBR & $0.0177^{* * *}$ & $0.0269^{* * *}$ & 0.0072 & $0.0476^{* * *}$ & -0.0083 & $0.1673^{* * *}$ & 1 \\
\hline
\end{tabular}

Note: ${ }^{* * *},{ }^{* *},{ }^{*}$ respectively expressed in the $1 \%, 5 \%, 10 \%$ level (bilateral) significant correlation.

Table 3. The regression analysis of acquisition behavior and enterprise value.

\begin{tabular}{ccccc}
\hline Variable & Coefficient & Standard error & T & P \\
B & -0.034 & 0.047 & -0.71 & 0.475 \\
LEV & $-3.452^{* * *}$ & 0.040 & -85.59 & 0.000 \\
TR & $0.0001^{* * *}$ & 0.000 & 4.96 & 0.000 \\
TAT & $0.224^{* * *}$ & 0.039 & 5.67 & 0.035 \\
RBR & $0.046^{* * *}$ & 0.006 & 7.42 & 0.000 \\
Ind & & Controlled & & \\
Year & & Controlled & & \\
Adj. $R^{2}$ & & 0.3287 & \\
F (sig) & & $650.81(0.000)$ & \\
\hline
\end{tabular}

Note: dependent variable: Q. ${ }^{* * *},{ }^{* *},{ }^{*}$ respectively expressed in the $1 \%, 5 \%, 10 \%$ level (bilateral) significant correlation.

Table 4. The regression analysis of investment efficiency, acquisition behavior and enterprise value.

\begin{tabular}{ccccc}
\hline Variable & Coefficient & Standard error & T & P \\
\hline IV & $-3.025^{* * *}$ & 0.394 & -7.67 & 0.000 \\
B & $-0.312^{* * *}$ & 0.051 & -6.10 & 0.000 \\
B*IV & $5.012^{* * *}$ & 0.409 & 12.24 & 0.000 \\
LEV & $-3.321^{* * *}$ & 0.040 & -81.96 & 0.000 \\
TR & $0.0002^{* * *}$ & 0.000 & 8.30 & 0.000 \\
TAT & $0.080^{* *}$ & 0.040 & 2.03 & 0.042 \\
RBR & $0.047^{* * *}$ & 0.006 & 7.64 & 0.000 \\
Ind & & Controlled & & \\
Year & & Controlled & & \\
Adj. $R^{2}$ & & 0.3397 & &
\end{tabular}

Note: dependent variable: Q. ${ }^{* * *},{ }^{* *}{ }^{*}{ }^{2}$ respectively expressed in the 1\%,5\%, 10\% level (bilateral) significant correlation.

necessary to mergers and acquisitions, if its target is to improve the value of enterprise. Many enterprises try to improve their enterprise value by mergers and acquisitions; but according to the research conclusion, the relationship between acquisition behavior and corporate value is not significant. Therefore, if the enterprise needs to consider carefully, its target for M\&A is to increase their value. 2) We also obtained the conclusion that the higher the efficiency of investment, the more significant influence acquisition behavior to increase the enterprise value. Small investors can get useful inspiration from this conclusion. When small and medium investors have interests in some companies, the change of the enterprise value before and after acquisition behavior of the 
companies can be analyzed according to the investment efficiency of enterprises in the past; therefore they can make the correct decisions.

\section{References}

[1] Langetieg, T. (1978) An Application of a Three-Factor Performance Index to Measure Stockholders Gains from Merger. Journal of Financial Economics, 6, 365-384. http://dx.doi.org/10.1016/0304-405X(78)90010-7

[2] Jarrel, and Bradley (1986) How Mismatched Managements Can Kill a Deal. Merger and Acquisitions, 3-4, 47-53.

[3] Palepu, Healy and Rubaek (1989) Mergers and Acquisitions, Human Resource Issues and Outcomes: A Review and Suggested Typology. Journal of Management Studies, 26, 271-289. http://dx.doi.org/10.1111/j.1467-6486.1989.tb00728.x

[4] Feng, G.F. and Wu, L.J. (2001) An Empirical Study on the Performance of Listing Corporation in China. Economic Research, 1, 54-61.

[5] Li, X.D., Zhu, H.L. and Zhang, B. (2003) Research on the Efficiency of Listing Corporation Merger Based on DEA. Economic Research, 10, 15-24.

[6] Xu, M.S. and Gao, X.H. (1997) Research on the Regional Role and Measurement Standard of Financial Center. Urban Finance in China, 9, 8-11.

[7] Yang, Y.J. (2007) Study on Optimal Financing Contract of Knowledge Based on Enterprises. Economic Management, 12, 14-20.

[8] Lu, F.C., Ning, L. and Hu, P.B. (2009) How the Government Acts to Promote Entrepreneurship. Economic Management, 7, 13-20. 